Review Article

\title{
Chlamydial infections in man
}

\author{
G.L. Ridgway \\ Department of Clinical Microbiology, University College Hospital, London WC1E 6AU, UK.
}

The earliest reference to a disease now known to be of chlamydial aetiology is to be found in the EBERS papyrus (1500 B.C.). A cicatrizing eye disease, and its treatment with copper salts, is described. This disease was first called 'trachoma' (rough eye) in A.D. 60 by the Sicilian physician Pedonius Diascarides. Moses' warning concerning the 'running issue of his flesh' (Leviticus 15 vv. 1-2) may be a description of urethritis; of which Chlamydia trachomatis is an important cause. The first recognition of the atypical pneumonia subsequently termed psittacosis is generally credited to Ritter (1880), who also noted a possible association with exotic birds. At the turn of the century, Halberstaedter \& von Prowazek (1907) described the intraepithelial inclusions characteristic of the organism causing trachoma. Not long after, similar inclusions were found in non-gonococcal ophthalmia neonatorum (inclusion blenorrhoea), urethritis and cervical infection (Fritsch et al., 1910). Whilst the psittacosis agent, and the agent of lymphogranuloma venereum (LGV) (possibly described first by Hunter in his 1786 Treatise on Venereal Disease), had been cultured in the yolk sac of the embryonated hen's egg since the $1930 \mathrm{~s}$, culture of the trachoma agent eluded efforts until the report by T'ang et al. in 1957. From that point in time, progress was rapid. Gordon et al. (1969) described improved cell culture techniques on which modern methods are based. The controversy over whether Chlamydia was a virus or bacterium was resolved by Moulder (1966). The organism is incontrovertibly a bacterium, with affinities to the Gram negative cocci.

The 1960s and 1970s produced an explosion of epidemiological publications, mainly concerned with Chlamydia trachomatis infection. Chlamydia psittaci, on the other hand, is primarily a pathogen of other animals, including birds, and it attracted comparatively little interest in the medical press, until recently. Chlamydial diseases in man are common, and assume many forms, but they are certainly underdiagnosed.

Correspondence: G.L. Ridgway, M.D., M.R.C.Path

Received: 24 October 1985.

\section{Chlamydia psittaci}

Chlamydia psittaci is classically associated with contact with psittacine birds, yet the organism is widely distributed in nature. Other birds such as ducks and pigeons harbour the organism. Sheep, goats and cattle suffer abortions and arthritis due to the organism, and the domestic cat is liable to feline kerato-conjunctivitis and pneumonia. The infection is sexually transmitted. in many instances. The association of infections of animals other than the parrot family with man is unclear, but they are believed to be generally of low communicability. However, Beer et al. (1982) and Johnson et al. (1985) reported cases of chlamydial infection in pregnancy, all following contact with infected sheep. Johnson (1983) noted reports of human infections associated with bovine chlamydial pneumonia, and bovine encephalomyelitis, and Stepanek et al. (1983) described serological changes and urogenital symptoms in men and women in contact with bovine chlamydiosis. Endocarditis is well known to be a complication of 'atypical' pneumonia caused by $C$. psittaci, but Regan et al. (1979) described a case with both endocarditis and glomerulonephritis probably caused by the feline conjunctivitis agent. Cases of conjunctivitis in cat owners are well documented (Johnson, 1983).

The true incidence of psittacosis in England is not known. Nagington (1984) reported that in Cambridge between 1975-1983, among a population of around 300,000 , there were 150 illnesses with serological evidence of chlamydial infection. Respiratory illness was evident in 110 patients, although in only $17 \%$ could contact with birds be implicated in the aetiology. More detailed examination of the results from one general practice in the survey showed an incidence of 1 in 200 (compared to 1 in 2,000 in the total study group). This may reflect a more determined use of diagnostic facilities by this practice, but more importantly suggests that the overall figures are an underestimate. In the general practice group, there was an association between serological evidence of $C$. psittaci and attendance at school. Pether et al. (1984) reported 
an outbreak of a mild coryza-like illness amongst 20 pupils and 4 adults in a boys' boarding school. Diagnosis was again based on serological criteria, using a complement fixation test (CFT), and immunofluorescence test, both detecting chlamydial group antibody. A source for the epidemic was not found. Although a non-avian source could explain the occurrence of respiratory symptoms milder than in classical psittacosis, human to human transmission of the infection is a distinct possibility. Schofield \& Keal (1986) report a case of sub-acute thyroiditis possibly caused by $C$. psittaci infection, basing the diagnosis on a greater than four-fold fall in complement fixing antibody. The patient gave no history of contact with birds, and suffered no genito-urinary symptoms.

The detection of circulating anti-chlamydial antibodies for clinical diagnosis or epidemiological studies presents difficulties. The complement fixation test (CFT) will not differentiate between infection by C. psittaci or C. trachomatis, because complement fixing antibody is directed against a genus-specific lipopolysaccharide. Many outbreaks ascribed to $C$. psittaci are based on serological results to groupreactive tests, and may therefore reflect antibody to $C$. psittaci, C. trachomatis or be of anamnestic origin. Chlamydial antibody levels in the general population are high, and vary between geographical areas. The source of this antibody is largely unknown. Recent studies suggest that an atypical chlamydial agent (designated IOL-207, or TW-183), with characteristics of both $C$. psittaci and $C$. trachomatis, may be involved. Burney et al. (1984) reported an increasing incidence of antibody to the agent IOL-207 in children over 5 years of age, compared to a low incidence of $C$. trachomatis antibody in children under 7 years, and suggest that the IOL-207 antibody is acquired through contact at school. Saikku et al. (1985) related an epidemic of mild pneumonia among school children in Finland to infection by TW-183, an atypical agent possibly identical to IOL-207. These two papers add weight to the concept of human to human transmission of chlamydial pneumonia.

\section{Chlamydia trachomatis}

C. trachomatis is almost exclusively a human parasite. Indeed, research into infection caused by this organism has been hampered by the lack of a suitable nonhuman animal host. During the past 25 years the broad spectrum of diseases associated with $C$. trachomatis has become apparent. The classical studies of Halberstaedter \& von Prowazek (1907) on trachoma were soon confirmed and extended. Studies on the role of $C$. trachomatis have shown that it causes genital infections in $35-60 \%$ of cases of non-gonococcal urethritis (Oriel \& Ridgway, 1982a). About $25 \%$ of men with gonococcal urethritis have concurrent infection with $C$. trachomatis. The treatment of gonococcal urethritis with beta-lactam antibiotics, or spectinomycin has no effect on the chlamydial infection, and these men will return with persistent post-gonococcal urethritis (PGU). Epididymitis in young adult males frequently has a chlamydial aetiology. Five of six patients under the age of 35 years investigated by Berger et al. (1978) were found to have C. trachomatis in epididymal aspirates; none yielded Neisseria gonorrhoeae. The role of $C$. trachomatis in prostatitis is more controversial, current evidence does not suggest that it is a major cause of either the acute or chronic form. Non-specific proctitis is an ill-defined condition of homosexual males practising peno-rectal intercourse. C. trachomatis does not appear to be a major cause although it has been recovered in rectal specimens from both asymptomatic and symptomatic patients (Munday \& Taylor-Robinson, 1983).

Chlamydial infection in women is less well appreciated, owing to a lack of specific symptoms. As with gonococcal infection, the patient may be asymptomatic, or complain of a vaginal discharge. Examination of the cervix yields few clinical clues, although Brunham et al. (1984) recently demonstrated the relationship of muco-purulent cervical discharge and absence of $N$. gonorrhoeae with $C$. trachomatis infection. C. trachomatis is recovered from the cervix in $45-68 \%$ of contacts of men with Chlamydia positive non-gonococcal urethritis (NGU) but from only․ㅡ $4-18 \%$ of contacts of men with Chlamydia-negative NGU. Over $80 \%$ of female source contacts of men with chlamydial urethral infection yield isolates. More disturbing, is the appreciation that some $12-31 \%$ of all women attending a sexually transmitted diseases (STD) clinic will yield $C$. trachomatis from cervical specimens (Oriel \& Ridgway, 1982a). Elsewhere isolation rates vary between $3 \%$ in family planning clinics, $5-9 \%$ in gynaecological clinics, to $16 \%$ in patients presenting for termination of pregnancy. Isolation rates of between 4 and $21 \%$ have been reported from the cervices of pregnant women (Hare \& Thin, 1983). Concurrent infection of the cervix and urethra is not uncommon. Approximately $50 \%$ of women with cervical gonorrhoea also have chlamydial infection. This is double the incidence in men with gonorrhoea, and may be evidence for persistent latent chlamydial infection (Oriel \& Ridgway, 1982b), a phenomenon well established in animals with $C$. psittaci infection. As is the case with gonococcal infection in men, betalactam antibiotics will be ineffective against the chlamydial infection. Since there is no female counterpart of post-gonococcal urethritis (PGU), the infection may go unnoticed. Little is known of the long term effect of cervical chlamydial infection, and an association with cervical dysplasia is a possibility (Hare \& Thin, 1983). 
The most important sequel to cervical infection in women is pelvic inflammatory disease (PID). The organism has been isolated from inflamed fallopian tubes by a number of workers (Weström \& Mårdh, 1982). There is controversy as to the incidence of chlamydial PID, but it is clear that the organism is an important cause, and in many countries a more frequent cause, than the gonococcus. In addition, the clinical course of gonococcal PID is generally more acute than chlamydial PID, so that women with the former are more likely to present in hospital than with the latter. Infection of the fallopian tubes probably ascends from the cervix, a concept supported by increasing evidence of endometritis associated with $C$. trachomatis (Paavonen et al., 1985). The consequences of salpingitis undiagnosed and untreated with specific chemotherapy include infertility and an increased incidence of ectopic pregnancy. Weström \& Mårdh (1982) estimate that $17 \%$ of women are infertile after one attack of salpingitis, owing to post-infection tubal damage. The risk of ectopic pregnancy is increased up to 10 -fold. Kane et al. (1984) noted a significantly higher incidence of chlamydial antibody in infertile women $(22 \%)$ compared to a control group $(11.5 \%)$. Further, they noted that infertile women with tubal obstruction had a greater prevalence of antichlamydial antibody $(35.7 \%)$ than infertile women with normal fallopian tubes $(11 \%)$. The relationship of chlamydial cervical infection to fetal death requires further study. Martin et al. (1982) reported fetal death in $30 \%$ of infected mothers, compared to $11 \%$ of the uninfected control group.

\section{Chlamydial conjunctivitis}

Chlamydial conjunctivitis occurs in both adults and neonates. In the Third World, trachoma remains an important cause of preventable blindness. Specific serotypes of $C$. trachomatis are responsible, along with poor hygiene conditions. In areas where the disease is hyperendemic, up to $95 \%$ of the population may show evidence of active or inactive trachoma (Darougar \& Jones, 1983). In developed countries, a milder form of conjunctivitis (paratrachoma) is found, caused by the genital serotypes of $C$. trachomatis. The disease is usually associated with sexually transmitted infections. Progression of the disease to pannus and scarring is unusual, but well documented. Chlamydial punctate keratoconjunctivitis is a complication occasionally seen, and may lead to persistent clouding of the cornea.

Chlamydial ophthalmia neonatorum is estimated to be some 5 times as common as gonococcal ophthalmia (Dunlop, 1975). The incubation period (3rd-14th day of life) is longer than for gonococcal infection and clinical differentiation from gonoccal ophthalmia is not possible. Dual infections are not uncommon. Silver nitrate prophylaxis is not effective, and the use of chloramphenicol eye drops is not only ineffective, but may delay diagnosis. The naso-pharynx may be colonized, leading to rhinitis and secretory otitis media. A distinctive pneumonitis appearing between the 4th and 12th weeks of life has been identified (Beem \& Saxon, 1977). Chest radiography shows hyperexpansion, with symmetrical diffuse interstitial and patchy alveolar infiltrates. High specific IgG and IgM titres are found, and this is one situation where serological investigation may assist diagnosis. The condition is almost certainly underdiagnosed in the UK. C. trachomatis has been isolated from the vagina and rectum of neonates, although a relationship to disease in these sites is unproven. Rees et al. (1977) noted that the gestation period was under 37 weeks in $41 \%$ of a group of babies with chlamydial ophthalmia, and that 2 of these babies had ventricular septal defects. Further studies on this aspect of chlamydial infection are required.

\section{Lymphogranuloma venereum}

Lymphogranuloma venereum (LGV) is a sexually transmitted disease caused by $C$. trachomatis serotypes $\mathrm{L}_{1} \mathrm{~L}_{2}$ and $\mathrm{L}_{3}$. Unlike most other forms of chlamydial infection the main pathology is due to involvement of lymphoid tissue rather than epithelial surfaces. The disease is common in tropical and sub-tropical countries. The primary genital lesion is transitory, and particularly in women may go unnoticed. Regional lymphadenopathy appears from 2 to 6 weeks after the primary lesion, involving the inguinal nodes if the lesion was vulval or penile, or the iliac nodes if the lesion was intra-vaginal. Suppuration of the nodes occurs, and the inguinal nodes break down to form multiple discharging sinuses. Tertiary manifestations include genital elephantiasis, rectal stricture, fistulae and carcinomatous change in the rectum. Secondary necrotic lesions lead to tissue loss, termed esthiomene. The infection may be refractory to specific chemotherapy.

\section{Reiter's syndrome and miscellaneous associations}

C. trachomatis has been implicated in a number of miscellaneous conditions. The most important and best researched of these, is sexually acquired reactive arthritis, including Reiter's syndrome. The subject has been recently reviewed by Keat (1983). Approximately $1 \%$ of men with NGU will develop arthritis, involving knees, ankles, feet or wrists. The classic triad of Reiter's syndrome (arthritis, non-gonococcal urethritis and ocular inflammation) develops in about one 
third of these patients. Sexually acquired reactive arthritis is considerably less common in women. The involvement of $C$. trachomatis in Reiter's syndrome is well summarized in a recent leading article in the Lancet (1985). Epidemiological, microbiological and immunological evidence all indicate a causal role for the organism, although its specific association with HLA-B27 antigens in this condition is unclear. Reiter's syndrome may also result from gastro-intestinal infection, when $C$. trachomatis is not the cause.

Reports of other clinical syndromes associated with C. trachomatis are sporadic. Tack et al. (1980) recovered $C$. trachomatis from the lower respiratory tract of 6 adults with pneumonia. Four of these patients were immunosuppressed, and also yielded cytomegalovirus. Antibody to $C$. trachomatis was not detected in any patient. Komaroff et al. (1981) found serological evidence of chlamydial infection in 4 of 19 patients with community acquired pneumonia. Cunningham et al. (1986) describe a patient with T-cell lymphoblastic lymphoma who had serological evidence of $C$. trachomatis pneumonia. Culture was negative, and unfortunately they were only able to estimate antibody on a single occasion. Results were suggestive of infection with $C$. trachomatis serotypes D-K (i.e. genito-urinary origin). A single diagnostic titre for chlamydial infection is difficult to define, and serology should be used as an adjunct to chlamydial isolation, particularly when novel clinical manifestations are being described. Other reported associations with C. trachomatis include endocarditis (van der BelKahn et al., 1978), myocarditis (Ringel et al., 1982) and meningo-encephalitis (Myhre \& Mårdh, 1981). All were based on micro-immunofluorescent antibody testing.

\section{References}

BEER, R.J.S., BRADFORD, W.P. \& HART, R.J.C. (1982). Pregnancy complicated by psittacosis acquired from sheep. British Medical Journal, 284, 1156.

BEEM, M.O. \& SAXON, E.M. (1977). Respiratory tract colonisation and a distinctive pneumonia syndrome in infants infected with C. trachomatis. New England Journal of Medicine, 296, 306.

BERGER, R.E., ALEXANDER, E.R., MONDA, G.D., ANSELL, J., MCCORMICK, G.' \& HOLMES, K.K. (1978). C. trachomatis as a cause of 'idiopathic' epidydimitis. New England Journal of Medicine, 298, 301.

BRUNHAM, R.C., PAAVONEN, J., STEVENS, C.E., KIVIAT, N., KUO, C-C., CRITCHLOW, C.W. \& HOLMES, K.K. (1984). Mucopurulent cervicitis - the ignored counterpart in women of urethritis in men. New England Journal of Medicine, 311, 1.

BURNEY, P., FORSEY, T., DAROUGAR, S., SITTAMPALAM, Y., BOOTH, P. \& CHAMBERLAIN, R. (1984). The

\section{Conclusions}

Diagnostic facilities for chlamydial infection are now widely available. In particular, antigen detection systems based on immunofluorescence or enzyme-linked immunoassay are now highly sensitive and specific, allowing many laboratories without cell culture facilities to make a positive diagnosis. However, a note of caution is necessary. Jones \& Taylor-Robinson (1983) suspect that false-positive chlamydial isolations are to be found in the literature. They add that the replacement of cell-culture by immunofluorescent monoclonal antibody detection systems for direct detection of elementary bodies may lead to a number of cases of disease being falsely attributed to chlamydial infection, owing to the detection of fluorescing particles that are not chlamydial. This is particularly important where such tests are used in circumstances for which they were not designed, for example in apparent extra-genital manifestations of chlamydial infection. This problem is less likely to occur with enzyme immunoassay, but the sensitivity and specificity of these methods require confirmation. The interpretation of chlamydial antibody titres is difficult, even with the more specific micro-immunofluorescence test, and caution is again necessary in attributing a chlamydial aetiology to a clinical condition. Nevertheless, $C$. psittaci and $C$. trachomatis are important human pathogens. Whilst much remains to be learned of their epidemiology, and the pathogenesis of human infection, enough is known to justify? diagnostic facilities on a wider scale than presently available. Such facilities are of limited value unless the clinician is aware of the possibility of chlamydiae as aetiological agents in the disease presenting to them. epidemiology of chlamydial infections in childhood: A serological investigation. International Journal of Epidemiology, 13, 491.

CUNNINGHAM, D., GILCHRIST, N.L., LEE, F.D., HAXTON, M., HEPPLESTON, A., FOREST \& G.J. SOUKOP, M. (1986). T-cell lymphoblastomic lymphoma of the uterus and Chlamydia trachomatis. Postgraduate Medical Journal, 62, 55.

DAROUGAR, S. \& JONES, B.R. (1983). Trachoma. British Medical Bulletin, 39, 117.

DUNLOP, E.M.C. (1975). Sticky eye in the newborn. British Medical Journal, 271, 333.

FRITSCH, H.O., HOFSTÄTTER, A. \& LINDNER, K. (1910). Experimentelle studien zur trachomfrage. Graefe's. Archiv für Ophthalmologie. 76, 547.

GORDON, F.B., HARPER, I.A., QUAN, A.L., TREHARNE, J.D., DWYER, R.St.C, \& GARLAND, T.A. (1969). Detection of chlamydia in certain infections of man. I. Laboratory 
procedures, comparison of yolk sac and cell culture for detection and isolation. Journal of Infectious Diseases, 120, 451.

HALBERSTAEDTER, L. \& von PROWAZEK, S. (1907). Über zilleinschlüsse parasitärer Natur beim Trachom. Arbeiten aus dem Kaiselichen Gesundheitsamke, 26, 44.

HARE, M.J. \& THIN, R.N. (1983). Chlamydial infection of the lower genital tract. British Medical Bulletin, 39, 138.

JOHNSON, F.W.A. (1983). Zoonoses in practice: chlamydiosis. British Veterinary Journal, 139, 93.

JOHNSON, F.W.A., MATHESON, B.A., WILLIAMS, H., LAING, A.G., JANDIAL, V., DAVIDSON-LAMB, R., HALLIDAY, G.J., HOBSON, D., WONG, S.Y., HADLEY, K.M., MOFFAT, M.A. \& POSTLETHWAITE, R. (1985). Abortion due to infection with Chlamydia psittaci in a sheep farmer's wife. British Medical Journal, 290, 592.

JONES, B.R. \& TAYLOR-ROBINSON, D. (1983). Observations on and future trends in chlamydial research. British Medical Bulletin, 39, 201.

KANE, J.L., WOODLAND, R.M., FORSEY, T., DAROUGAR, S. \& ELDER, M.G. (1984). Evidence of chlamydial infection in infertile women with and without fallopian tube obstruction. Fertility and Sterility, 42, 843.

KEAT, A. (1983). Reiter's syndrome and reactive arthritis in perspective. New England Journal of Medicine, 309, 1607.

KOMAROFF, A., AVONSON, M. \& SCHACHTER, J. (1981). Chlamydia trachomatis infection in adults with community-acquired pneumonia. Journal of the American Medical Association. 245, 1319.

LEADING ARTICLE. (1985). Is Reiter's syndrome caused by Chlamydia? Lancet, i, 317.

MARTIN, D.H., KOUTSKY, L., ESCHENBACH, D.A., DALING, J.R., ALEXANDER, E.R., BENDETTI, J.K. \& HOLMES, K.K. (1982). Prematurity and perinatal mortality in pregnancies complicated by maternal $C$. trachomatis infections. Journal of the American Medical Association, 247, 1585.

MOULDER, J.W. (1966). The relation of the psittacosis group (chlamydia) to bacteria and viruses. Annual Review of Microbiology, 20, 107.

MUNDAY, P.E. \& TAYLOR-ROBINSON, D. (1983). Chlamydial infection in proctitis and Crohn's disease. British Medical Bulletin, 39, 155.

MYHRE, E.B. \& MÅRDH, P-A. (1981). Chlamydia trachomatis infection in a patient with meningoencephalitis. New England Journal of Medicine, 304, 910.

NAGINGTON, J. (1984). Psittacosis/ornithosis in Cambridge 1975-1983. Journal of Hygeine, Cambridge, 92, 9.

ORIEL, J.D. \& RIDGWAY, G.L. (1982a). In Genital Chlamydial Infection. Edward Arnold: London.

ORIEL, J.D. \& RIDGWAY, G.L. (1982b). Epidemiology of chlamydial infection in the human genital tract. European
Journal of Clinical Microbiology, 1, 69.

PAAVONEN, J., RISTO, A., TEISALA, K., HEINDNEN, P., PUNNONEN, R., LEHTINEN, M., MIETTINEN, A. \& GRÖNROOS, P. (1985). Chlamydial endometritis. Journal of Clinical Pathology, 38, 726.

PETHER, J.V.S., NOAH, N.D., LAU, Y.K., TAYLOR, J.A. \& BOWIE, J.C. (1984). An outbreak of psittacosis in a boy's boarding school. Journal of Hygiene, Cambridge, 92, 337.

REES, E., TAIT, I.A., HOBSON, D. \& JOHNSON, F.W.A. (1977). Perinatal chlamydial infection. In Non-gonococcal Urethritis and Related Infection, Hobson, D. \& Holmes, K.K. (eds). American Society of Microbiology: Washington D.C.

REGAN, R.L., DATHAN, J.R.E. \& TREHARNE, J.D. (1979). Infective endocarditis with glomerulonephritis associated with cat chlamydia (C. psittaci) infection. British Heart Journal, 42349.

RINGEL, R.E., BRENNER, J.I., RENNELS, M.B., HUANG, S-W., WANG, S-P., GRAYSTON, J.T. \& BERMAN, M-A. (1982). Serologic evidence for $C$. trachomatis myocarditis. Pediatrics, 70, 54.

RITTER, J. (1880). Beitrage zur frage des pneumotyphus. Deutsche Archiv Klinische Medizinische, XXV, 53.

SAIKKU, P., WANG, S.-P., KLEEMOLA, M., BRANDER, E., RUSANEN, E. \& GRAYSTON, J.T. (1985). An epidemic of mild pneumonia due to an unusual strain of Chlamydia psittaci. Journal of Infectious Diseases, 151, 832.

SCHOFIELD, P.M. \& KEAL, E.E. (1986). Subacute thyroiditis associated with Chlamydia psittaci infection. Postgraduate Medical Journal, 62, 33.

STEPANEK, O., JINDRICHOVA, J., HORACEK, J. \& KRPATA, V. (1983). Chlamydiosis in cattle and man: an epidemiologic and serologic study. Journal of Hygiene, Epidemiology, Microbiology and Immunology, 27, 445.

TACK, K.J., RASP, F.L., HANTO, D., PETERSON, P.K., O'LEARLY, M., SIMMONS, R.L. \& SABATH, L.D. (1980). Isolation of $C$. trachomatis from the lower respiratory tract of adults. Lancet, i, 116.

T'ANG, F.F., CHANG, H.L., HUANG, Y.T. \& WANG, K.C. (1957). Studies on the aetiology of trachoma with special reference to isolation of the virus in chick embryo. Chinese Medical Journal, 75, 429.

VAN DER BEL-KHAN, J.M., WATANAKUNAKORN, C., MENEFEE, M.G., LONG, H.D. \& DICTER, R. (1978). C. trachomatis endocarditis. American Heart Journal, 95, 627.

WESTRŐM, L. \& MÅRDH, P-A. (1982). Genital chlamydial infections in the female. In Chlamydial Infections, Mårdh, P-A., Holmes, K.K., Oriel, J.D., Piot, P. \& Schachter, J. (eds). pp. 121-140. Elsevier Biomedical Press: Amsterdam. 